\title{
Corrigendum
}

\section{Corrigendum to "The Transcription Factor Bach1 Suppresses the Developmental Angiogenesis of Zebrafish"}

\author{
Li Jiang, ${ }^{1}$ Meng Yin, ${ }^{2}$ Jie Xu, ${ }^{1}$ Mengping Jia, ${ }^{1}$ Shaoyang Sun, ${ }^{3}$ Xu Wang, ${ }^{3}$ Jianyi Zhang, ${ }^{4}$ \\ and Dan Meng $\mathbb{1}^{1}$ \\ ${ }^{1}$ Department of Physiology and Pathophysiology, School of Basic Medical Sciences, Fudan University, Shanghai 200032, China \\ ${ }^{2}$ Department of Cardiothoracic Surgery, Shanghai Children's Medical Center, Shanghai Jiao Tong University School of Medicine, \\ Shanghai 200127, China \\ ${ }^{3}$ Department of Biochemistry and Molecular Biology, School of Basic Medical Sciences, Fudan University, Shanghai 200032, China \\ ${ }^{4}$ Department of Biomedical Engineering, School of Medicine, University of Alabama at Birmingham, Birmingham, AL 35294, USA \\ Correspondence should be addressed to Dan Meng; dmeng@fudan.edu.cn
}

Received 3 September 2018; Accepted 5 September 2018; Published 25 October 2018

Copyright ( $2018 \mathrm{Li}$ Jiang et al. This is an open access article distributed under the Creative Commons Attribution License, which permits unrestricted use, distribution, and reproduction in any medium, provided the original work is properly cited.

In the article titled "The Transcription Factor Bach1 Suppresses the Developmental Angiogenesis of Zebrafish" [1], the quality of the images for Figures 2(a) and 3(a) is low. Higher-quality images for Figures 2(a) and 3(a) and merged image of bright field and fluorescent image for Figure 3(a) are shown as follows. 


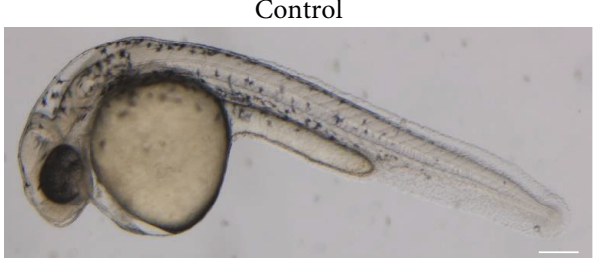

(A)

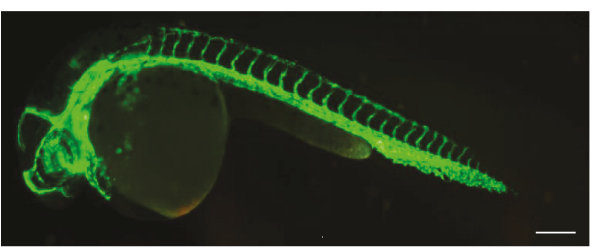

(C)

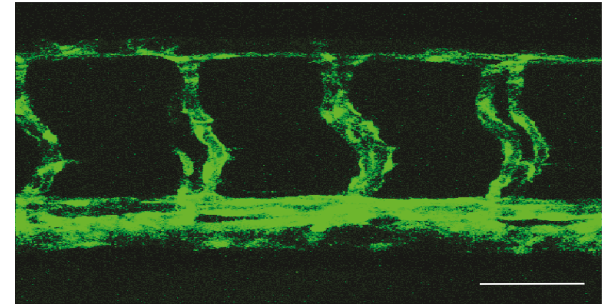

(E)

Bach1 mRNA

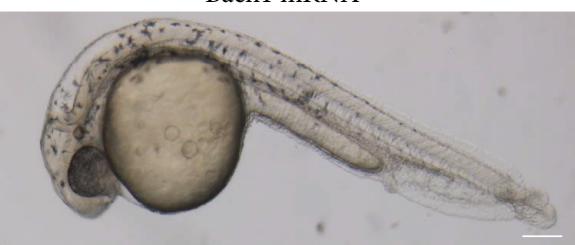

(B)

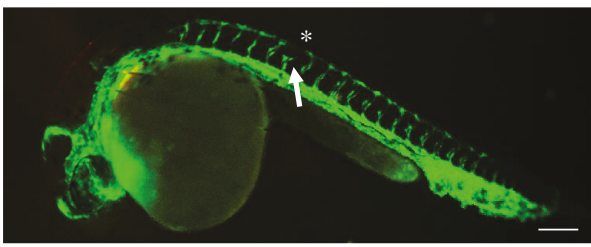

(D)

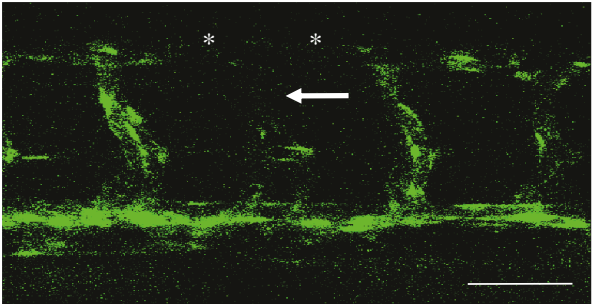

(F)

(a)

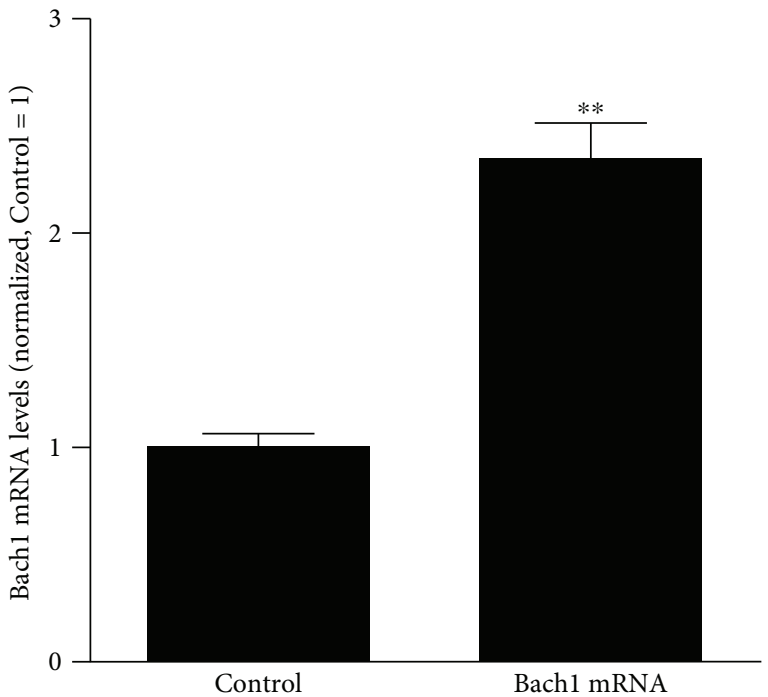

(b)

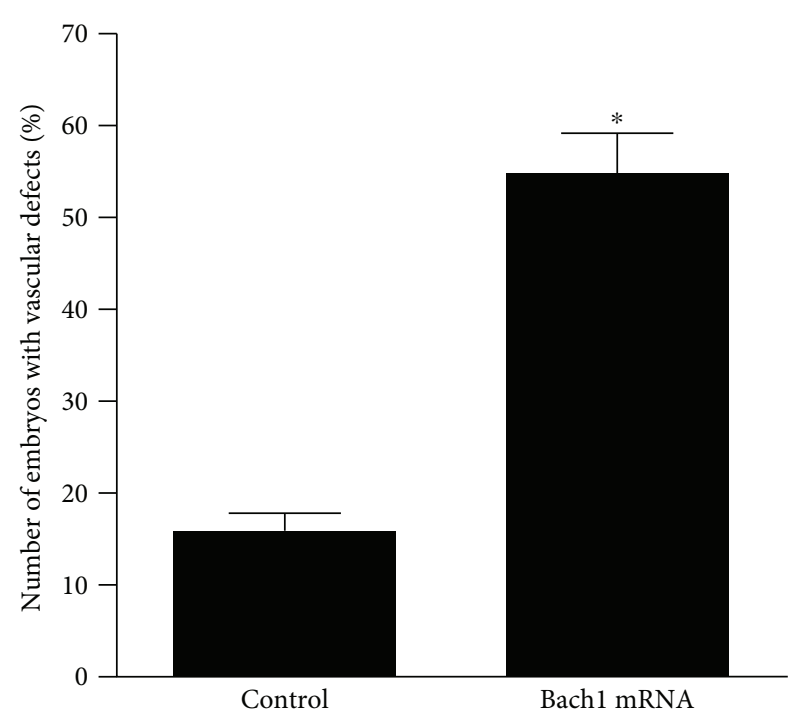

(c)

Figure 2 

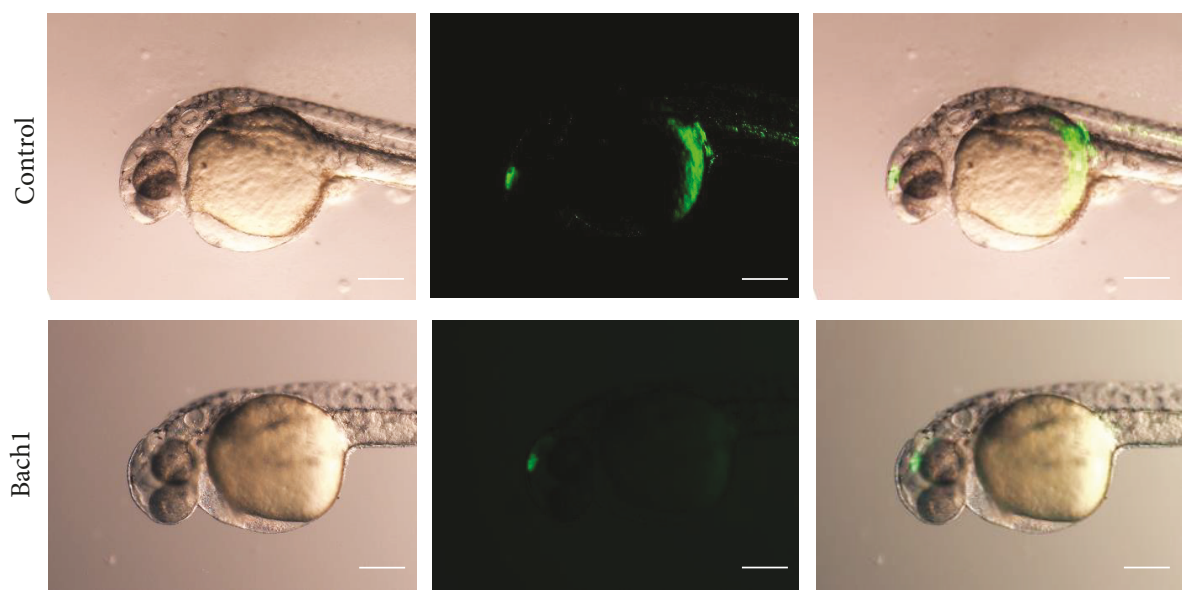

(a)

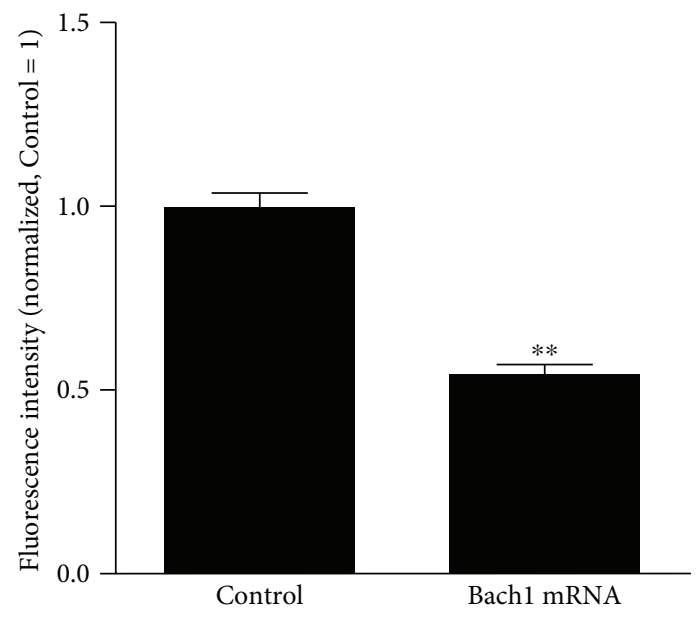

(b)

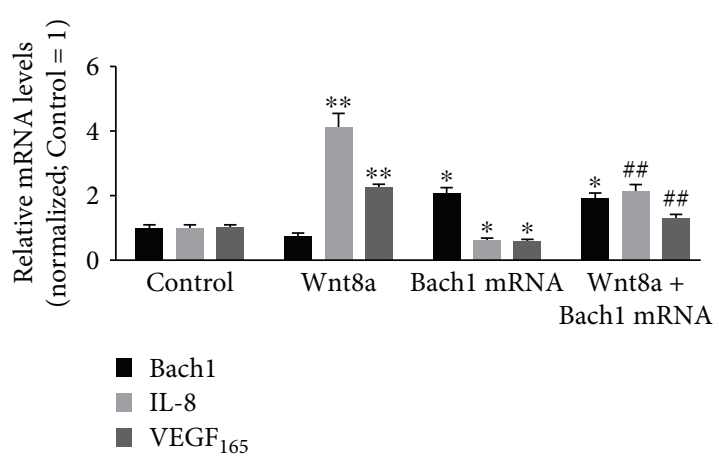

(c)

Figure 3

\section{References}

[1] L. Jiang, M. Yin, J. Xu et al., "The transcription factor Bach1 suppresses the developmental angiogenesis of zebrafish," Oxidative Medicine and Cellular Longevity, vol. 2017, Article ID 2143875, 10 pages, 2017. 


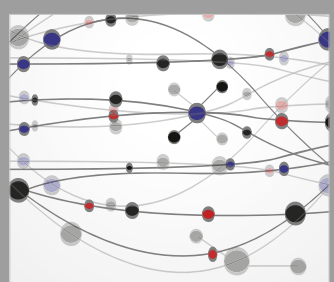

The Scientific World Journal
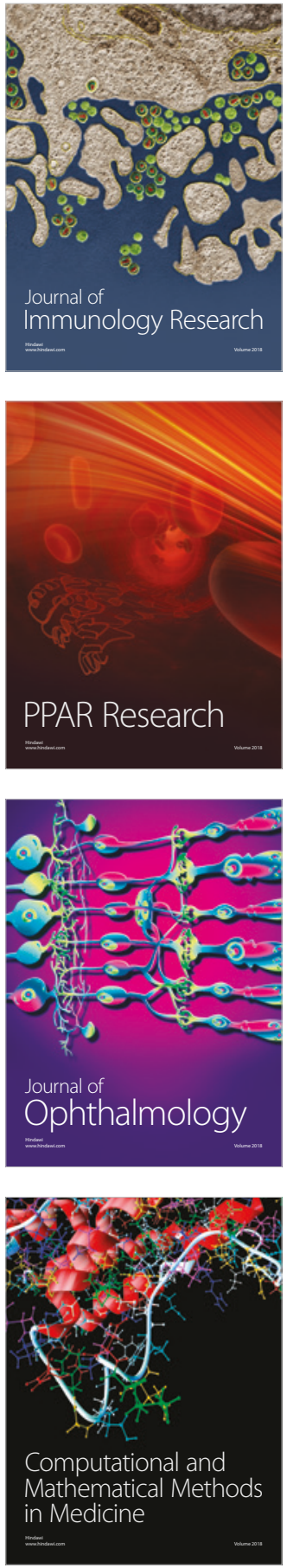

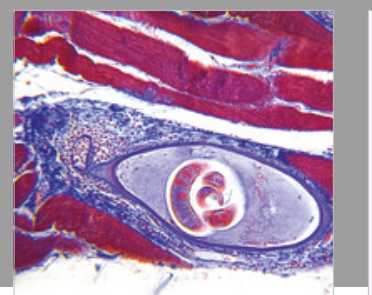

Gastroenterology Research and Practice

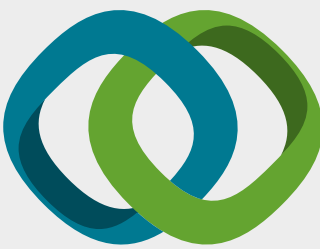

\section{Hindawi}

Submit your manuscripts at

www.hindawi.com
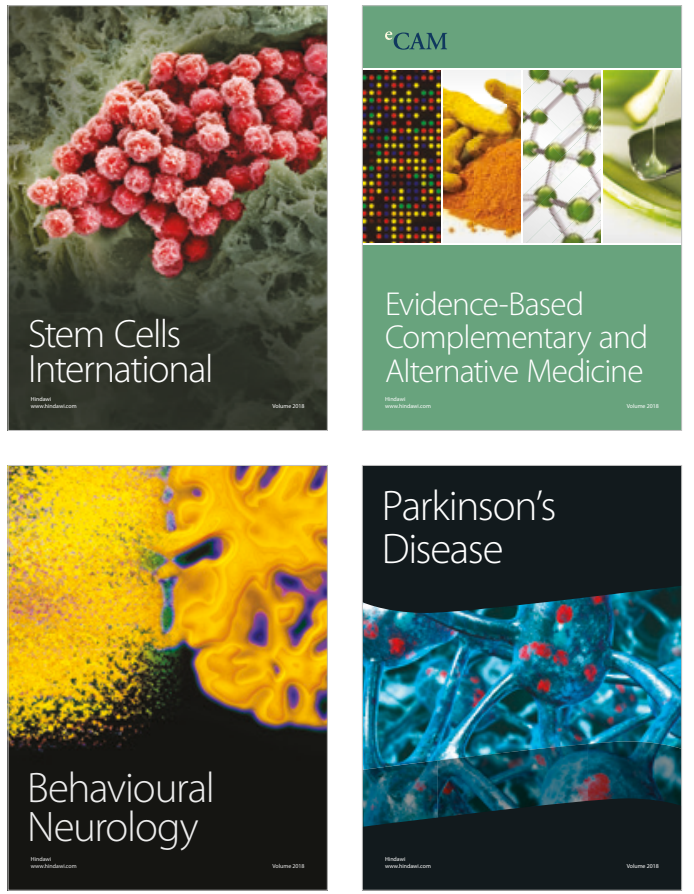

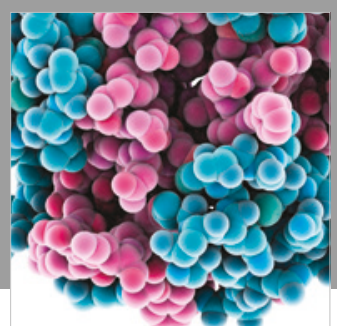

ournal of

Diabetes Research

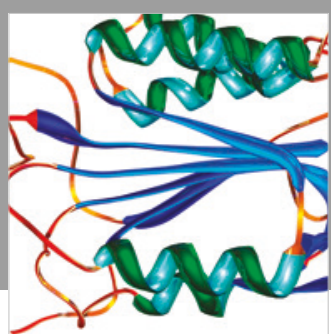

Disease Markers
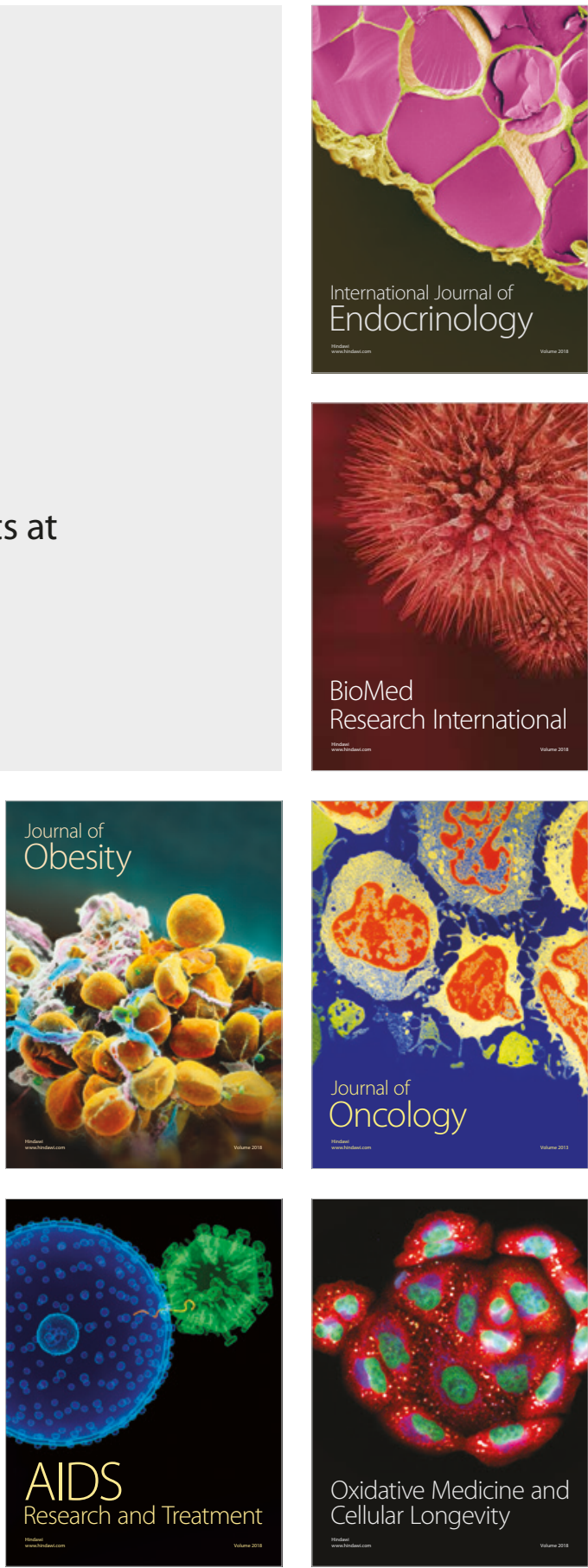